\title{
EL CRIMEN DE VILLAVICIOSA, DE RAMÓN DE NAVARRETE: ENTRE LA CRÓNICA DE SOCIEDAD Y EL RELATO DE MISTERIO
}

\author{
Enrique Rubio CREmades \\ Universidad de Alicante
}

Ramón de Navarrete (1818-1897), cuya polifacética labor literaria le convirtió en una de las más célebres figuras de su época, es hoy en día una curiosa rareza bibliográfica. Sus novelas, olvidadas. Sus artículos de crítica relegados a un segundo plano, y sus piezas teatrales postergadas por los estudiosos de la dramaturgia. Sin embargo, en su época gozó de una fama fuera de lo común. Valera lo incluye en el mundo de ficción de Juanita la Larga como conocedor perfecto de la aristocracia y de las costumbres. Su seudónimo, Asmodeo, le inmortalizaría como el gran conocedor de la sociedad de buen tono, imprescindible en cualquier sarao o reunión de la burguesía y aristocracia madrileñas. Escritor que también se le puede identificar con el personaje de Pequeñeces, del padre Coloma, llamado Pedro López, cuyas crónicas sociales eran conocidísimas en la segunda mitad del siglo XIX. Incluso numerosísimas anécdotas sobre su persona, muy olvidadas, hacían sonreír al gran público de la época por sus excentricidades o rarezas. Por ejemplo, G. Cavestany (1917-1918), en sus memorias publicadas a principios del siglo XX, señala que Asmodeo cayó en la manía de guardarse en sus bolsillos los dulces y canapés que le servían en las fiestas, pese a gozar del bienestar que le proporcionaba el dinero. Fernández Almagro (1951: 57-58) recoge también esta anécdota popular en los ambientes aristocráticos. Apunta al respecto que «forraba de hule los bolsillos de su levita o de su frac para llevarse dulces y golosinas a su casa». Su celebridad como comediógrafo hizo posible que Galdós lo incluyera en sus Episodios 
Nacionales ${ }^{l}$. Otro tanto sucede con su faceta periodística, copiosísima y de múltiples contenidos y matices. Sus artículos solían estar firmados con su correspondiente nombre y apellido, aunque no desdeñaba otros patronímicos o seudónimos que tuvieron también una gran incidencia en los medios periodísticos, como Leporello, Pedro Fernández, Mefistófeles, José Núñez de Lara y Tavira, Pedro Fernández y Asmodeo o Marqués de Valle Alegre. Para cada uno de ellos reservaba la crónica teatral, de música y variedades o literaria en general.

Pese a no ocuparnos de su producción dramática ${ }^{2}$ y periodística ${ }^{3}$, pues sólo nos ceñimos a la novela y, en particular, a la titulada El crimen de Villavicio-

1. Ramón de Navarrete era el segundo jefe de Pepe García Fajardo en la redacción de La Gaceta y contertulio de los Socobios. Como es bien sabido Pepe Fajardo no sólo es protagonista de la novela Las tormentas del 48, sino también figura esencial en numerosos Episodios Nacionales. Los Socobios «dinastía de clérigos y seglares aclerigados, sanguijuelas del Reino y vampiros de la Administración», figuran también entre los contertulios de Ramón de Navarrete y celebridades de la época a través de su trasiego novelesco por los Episodios Nacionales de la segunda y tercera serie: Bodas reales, Las tormentas del 48, Narváez y Cánovas.

2. Su producción dramática, zarzuelas, adaptaciones y traducciones, constituyen hoy en día una auténtica rareza bibliográfica. La producción es la siguiente: Un enlace desigual. Drama, Madrid, Boix, 1841; La Perla de Barcelona. Comedia, Madrid, Boix, 1844; Benvenuto Cellini o el poder de un artista. Comedia, Madrid, Repullés, 1846; Las intrigas de una Corte. Comedia, Madrid, Repullés, 1846; Un cambio de mano. Comedia en dos actos escrita en francés por Mr. Bayard y arreglada a la escena por..., [sin lugar, ni imprenta], 1846; Dos hijas casaderas. Comedia, Madrid, Yenes, 1847; Memoria de dos jóvenes casados. Comedia en un acto arreglada a la escena por..., Madrid, Lalama, 1847; Las gracias de Gedeón. Juguete cómico, Madrid, Imprenta de J. González y A. Vicente, 1847; Por no explicarse. Comedia, Madrid, Repullés, 1847; Un pupitre y un retrato. Juguete cómico, Madrid, Repullés, 1851; Una mujer misteriosa. Comedia, Madrid, Imprenta que fue de Operarios a cargo de D. F. N. del Castillo, 1852; El amor por los balcones. Juguete cómico-lírico, Madrid, Lalama, 1853; Un viejo verde. Proverbio en un acto, Madrid, Biblioteca Dramática de V. Lalama, 1854; Más vale maña que fuerza. Proverbio en un acto, Madrid, 1856; La corte de Mónaco. Zarzuela, Madrid, Rodríguez, 1857; Un ente singular. Comedia, Salamanca, Est. Tip. del Hospicio, 1968; Un viaje a pie quieto. Juguete en un acto, Madrid, Imprenta de García Alambra, 1868; Inés ou La choute d'un ministre. Traduction par Carlos de Algarra, París, 1885; Los dominios blancos. Comedia en tres actos y en prosa, imitada del francés por..., Madrid, Imprenta de José Rodríguez [s.a.].

Sus adaptaciones fueron conocidísimas y la prensa recogió en sus correspondientes secciones dedicadas al teatro un singular número de adaptaciones, como las tituladas Está loca, Emilia y Don Rodrigo Calderón, traducida esta última al francés y representada con éxito en el teatro Odeón de París. De no menor consecución fueron sus adaptaciones tituladas Dos hijas casaderas, El agiotage o el oficio de moda, El Corregidor de Madrid, La Noche de San Bartolomé, Juana y Juanita, Mujer gazmoña y marido infiel, Los pavos reales, La Soirée de Gachupín, Los dominios blancos, etc.

De sus obras dramáticas originales ausentes en el prime listado de la presente nota y, por ende, no localizadas, aunque sí se sepa de su existencia gracias a las referencias de la prensa, podemos añadir la relación siguiente: Capricho de la fortuna (escrita por encargo de la reina Isabel II para el coliseo del real palacio y representada después en El Español a petición de su director Ventura de la Vega), La reina por fuerza, La huérfana de Amberes, La abuela, La ambición, Los últimos amores, Un casamiento a media noche, La hija del Regente, Genoveva, Odio y amor, Yerros de 
$s a^{4}$, no por ello silenciamos el resto de su producción periodística referida al género novela o a otras narraciones que complementan o ayudan a interpretar mejor el citado relato. En este sentido cabe señalar, como mención significativa, sus artículos sobre la novela publicados en el Semanario Pintoresco Español ${ }^{5}$. Es evidente que gracias al estudio de sus colaboraciones periodísticas podemos reconstruir su pasado literario, su credo estético, sus amistades y afinidades ideológicas. Por ejemplo, forma parte de la redacción de la revista satírico-literaria La Ortiga (1849), periódico poco adicto al Teatro Español y, sobre todo, a su comisario, Ventura de la Vega. Sus colaboraciones más interesantes en el Semanario Pintoresco Español tienen lugar a raíz del cese de Navarro Villoslada, en la época en la que figura Ángel Fernández de los Ríos como responsable de la sección literaria. Amistad también con Gabriel García Tassara, director de El Faro, y sus redactores, Francisco de Paula y Mellado y Luis González Bravo. Sus principales colaboraciones se insertan tanto en la prensa adscrita a la Unión Liberal $-E l$ Día, El Diario Español-, como a las de carácter misceláneo y de contenido eminentemente artístico o literario que en su día fueron muy cele-

juventud, Una mujer misteriosa, El grumete, La tutora, Un cambio de mano, Un día de libertad, Deshonor por gratitud, El perro del castillo, La vida por partida doble, Reinar contra su gusto, Clara Harlowe, La escuela de los amigos, Por no explicarse, La pena del Talión, Pecado y expiación, Cuando se acaba el amor, Ya es tarde, Una conspiración femenina, Un diablo con faldas, La viuda de quince años, La charlatanería, Un matrimonio a la moda, El robo de un hijo, Los pasteles de María Michón, La hermana del sargento, Un corazón maternal, Un viaje a América, El diablo son los nietos, La casa en rifa, Por un loro, Cambiar de sexo, El marido duende, Por quinientos florines, La cola del perro de Alcibíades, Un soldado voluntario, Lobo y cordero, La hechicera, Jóvenes y viejos, Cuando el diablo no tiene que hacer, A muertos y a idos, El pleito de San Doval, El fénix de los maridos, El primer hijo y La piel de León.

3. En época temprana inició sus colaboraciones periodísticas. Artículos de costumbres y de crítica que se encuentran en los periódicos madrileños El Siglo XIX, La Ortiga, Semanario Pintoresco español, El Faro, La Época, La Ilustración Española y Americana, La Moda Elegante, El Día, La Correspondencia, El Heraldo, El Tiempo, El Correo, El Diario español, entre otros. Especial incidencia tuvo Navarrete en la publicación La Época, pues fue director al fundarse en 1874, en su época afín a la Unión Liberal, ya que luego se convirtió en moderado y, desde la revolución de 1868 , en alfonsino.

4. La novela se publica en la imprenta del diario El Día. Publicación que también se editó en las imprentas de Pérez Dubrull y de Fortanet.Empezó a publicarse en 1881. Exiten cuatro colecciones. A partir del 4 de enero de 1920 cambia de formato. Con anterioridad apareció en Madrid un periódico homónimo en su título como El Día, gaceta política independiente, Madrid, Imprenta de El Día, 1858-1861.

5. La primera colaboración de R. de Navarrete en el Semanario Pintoresco Español se remonta al año 1840 con un artículo de crítica literaria sobre Campoamor (1840: 247-248). El artículo de mayor enjundia para el conocimiento y estudio de la novela de mediados del siglo XIX corresponde a su artículo «Literatura. La novela española» (1847: 82-84; 117-119 y 130-131). Durante los años 1850, 1851 y 1855 publicará diversos cuadros de costumbres, impresiones de viajes y relatos. 
bradas por la belleza de sus grabados, como La Ilustración Española y Americana, periódico editado y dirigido por su buen amigo Abelardo de Carlos. El seguimiento de sus escritos en la prensa permite al lector el conocimiento de una personalidad singular desconocida por el estudioso del siglo XIX, pues sus amistades, desencuentros y reencuentros con el mundillo literario de la época se pueden reconstruir a través de la prensa.

Respecto a sus novelas cabe señalar que tanto El crimen de Villaviciosa como El duque de Alcira (1890) son las dos últimas novelas escritas por Navarrete en plena época de madurez. Sin embargo fueron menos celebradas que sus relatos publicados con anterioridad, como Creencias y desengaños (1843), Madrid y nuestro siglo (1845-1846), Misterios del corazón (1849), Verdades y ficciones (1874) y Sueños y realidades (1878). Sólo una novela de Ramón de Navarrete apareció por entregas desde las páginas de una publicación periódica, la titulada Fenómenos psicológicos, de la que no conocemos una edición en forma de libro. El crimen de Villaviciosa a diferencia del resto de sus novelas se inscribe o inserta en un periodo histórico y literario propicio para la descripción y análisis de una causa criminal o proceso judicial. Las casas editoriales y los periódicos del último tercio del siglo XIX publicaron en sus páginas numerosas «Causas célebres» $\mathrm{O}$ «Crónicas de Tribunales» en donde se escrutaba y analizaba con minuciosidad tanto el móvil del crimen como las circunstancias que rodeaban al mismo. Recuérdense, por ejemplo, los célebres crímenes cometidos por estas fechas y comentados profusamente por los periódicos en los que, precisamente, colaboró el propio Ramón de Navarrete. El crimen de la calle Justa, el del Huerto Francés, el de don Nilo, el de Vicente Verdier, el del Capitán Sánchez, el de Gádor o el de la Guindalera no tienen nada que envidiar al más célebre de todos: el crimen de la calle de Fuencarral, novelado en varias ocasiones y llevado al cine en época temprana ${ }^{6}$. De igual forma Navarrete estaba familiarizado con el relato de crímenes, pues con anterioridad a la publicación de su novela El crimen de Villaviciosa habían aparecido en el mercado editorial obras que tuvieron una gran incidencia en este preciso contexto, como Crímenes célebres españoles (1859), Crimen, venganza y expiación (1863), El Sacamantecas (1881), El crimen de Berzocana (1880)... Por estas fechas se publicaron numerosísimos Procesos, como los editados por Manero, y obras que aluden directamente al célebre calabozo madrileño El Saladero, como en la novela de Navarrete. La Historia de El Saladero (1870-1871), de F. Morales Sánchez, El mundo del crimen (1888), de Freixá y Martí, Los procesos civiles (1884) de A. Sáez Domingo y El crimen de la calle Moncada (1886), de F. M. Car-

6. Vid. mi artículo «Entre el relato policiaco, realista y pseudofolletinesco: Piedad, historia de una joven desgraciada, de Mariana de Mendoza» (2005: 321-331) 
bonell, demuestran el interés del público por este tipo de obras en el último tercio del siglo XIX, de ahí que Ramón de Navarrete pagara tributo a un género cuyo contenido recrea y noveliza un hecho criminal, al igual que los célebres novelistas hicieran años más tarde, como Pérez Galdós -El crimen de la calle Fuencarral-, Florencio Luis Parreño -El crimen sacrílego-, Mariana de Mendoza-Piedad, historia de una joven desgraciada-, A. Moyano - El crimen del Halconero-, R. A. Torres y J. Rodríguez Castro -El crimen de las Lomas-, etc. Moda que también se extendió por Europa, como las célebres novelas de Montepin El crimen del teniente y El crimen de Asnières. El contenido de El crimen de Villaviciosa nada tiene que ver con sus anteriores relatos, pues éstos muestran otras intenciones y premisas. Por ejemplo, su novela Creencias y desengaños se circunscribe a una época en la que la producción novelística -en torno a la década de los años cuarenta de la centuria decimonónica- refleja las costumbres y el ambiente social contemporáneo, como por ejemplo las novelas Los cortesanos y la revolución, de E. de Tapia; La protección de un sastre de Miguel de los Santos Álvarez; El diablo las carga, de Ros de Olano; El poeta y el banquero. Escenas contemporáneas de la revolución española, de Pedro Mata. El diablo y yo, Los habitantes de la luna y Madrid y sus misterios, anónimas, entre otras, reflejan con precisión el contexto histórico y social, la lucha por la vida en época de guerras y estrecheces de toda clase, el poder del dinero y la falta de escrúpulos para conseguir dicho dinero mediante el juego, el casamiento interesado o de forma fraudulenta. Con razón el propio Navarrete en el inicio de su novela Creencias y desengaños escribe al respecto lo siguiente: «En nuestros días, en que las hadas y los magos han desaparecido, los verdaderos duendes somos nosotros, los novelistas, que escudriñamos en los misterios, que investigamos las causas de todos los sucesos, que nos introducimos en medio de todas las familias para revelar al mundo la historia de sus debilidades o de sus dolores» (1843: 3). Una novela que refleja el pesimismo y desengaño de Navarrete, pues la sociedad española de la época, año 1843, atraviesa unos momentos harto complejos y delicados: la caída de Espartero y la fortísima crisis económica que sufre España, precisamente, en el mencionado año. Pesimismo y desazón que subyacen en Creencias y desengaños ${ }^{7}$ y crítica social encauzada a través de una compleja peripecia argumental que será motivo central de sus novelas posteriores, como en el caso de Madrid y nuestro siglo. Navarrete

7. Leopoldo Augusto de Cueto alude, precisamente, al pesimismo de Navarrete en su novela: «[...] nosotros no creemos ni queremos creer que la sociedad sea hasta ese punto presa de la perversidad o de la desventura. Aún hay virtudes, aún hay nobles sentimientos, aún hay bellas acciones; y si fuese cierto que la virtud y su galardón no son en el mundo más que excepciones, todavía opinamos que debiera el novelista buscar cuidadosamente esas excepciones para oponerlas victoriosamente a la corrupción y a la inmoralidad», Revista de Madrid, Segunda Época, I, (1843: 485). 
describe el comportamiento humano, no expone teorías, sólo se limita a detallar casos, como en la última novela citada, ambientada en su mayor parte en la Plazuela de San Miguel y cuyos tipos descritos se acercan al Madrid de las novelas galdosianas, a la sociedad madrileña del último tercio del siglo $\mathrm{XIX}^{8}$. Escenas, situaciones que aparecen en el novelar de Navarrete durante la década de los años cuarenta y que parecen anticipar, al igual que otros novelistas, la aparición de la gran novela iniciada y cimentada por el propio Galdós (Brown: 1953 y 1956; Zavala: 1971). Es evidente la existencia de una novela de costumbres en la década de los años treinta y cuarenta. Navarrete es un eslabón importante, al igual que otros novelistas cuyas aportaciones permiten enriquecer el complejo panorama literario del segundo tercio del siglo XIX. Recientes publicaciones (Sebold, 2007) ahondan con precisión en las raíces de la novela realista. Relatos que tuvieron una función decisiva en la evolución del realismo y cuya aparición se fija en la década de los años cuarenta y finalización de la década en que se proclama la Septembrina o Revolución del 68. La plasmación y estudio de específicos casos de novelas y autores, como en el caso de W. Ayguals de Izco, corroboran la trascendencia e importancia de una generación que preparó y asentó los cimientos de la gran novela española del realismo español.

Es evidente que Ramón de Navarrete figura por derecho propio como uno de los precursores de la novela realista española, pese a que en su época fuera más conocido y celebrado como periodista-cronista de la sociedad de buen tono y autor de célebres piezas teatrales, cuyas representaciones le dieron una gran popularidad ${ }^{9}$. Precisamente ambas coordenadas literarias

8. La novela, en opinión de Navarrete, debe estudiar la sociedad, pues de esta forma las generaciones posteriores podrán conocer y estudiar con precisión las épocas pretéritas. Navarrete sitúa la acción en la plaza de San Miguel, emplazada entre la calle Mayor y la Cava de San Miguel. Sus personajes son vendedores de la plazuela, como la tía Juana, Mala Lengua, Manos Lisas, Bragazas. Fiel descripción del bajo mundo con aspiraciones sociales, como en las novelas galdosianas. Personajes campechanos, astutos, inteligentes que preludian el nuevo cambio social y su incorporación a la burguesía. Tipos filantrópicos como Gil Moraleja, antecedente inmediato del protagonista de la novela El amigo Manso, hombre bondadoso, bueno, profesor, cuyo ideal amoroso se centra en su discípula Inesita. Don Gil es bueno en el sentido estricto de la palabra y, a diferencia del personaje galdosiano, acabará casándose con su joven pupila Rita. Descripción, en definitiva, de un mundo social que en nada tiene que envidiar a los relatos o novelas realistas de la generación posterior.

9. Blanco y García refiere su incidencia e importancia en la escena española de esta época: «Don Ramón de Navarrete fue, durante un periodo muy largo, brazo auxiliar y proveedor fecundísimo de las empresas teatrales, dando tortura al ingenio propio y poniendo a contribución el de los autores parisienses. En el primer sentido figuran, como puntos cardinales de su repertorio, los dramas que siguen: Emilia, por sus rasgos de observación psicológica y social; Don Rodrigo Calderón o la caída de un Ministro, una de las primeras obras en que aparece como protagonista el célebre favorito, mucho antes de idear Ayala Un hombre de Estado, traducida y representada en francés [...] De la interminable serie de refundiciones, más o menos felizmente llevadas a cabo por Navarrete, 
se aúnan en su novela El crimen de Villaviciosa, pues su mundo de ficción tiene lugar entre aristócratas y un contexto social de muy parecido corte al desarrollado en sus piezas teatrales. Incluso algunos motivos de sus novelas publicadas en época de juventud aparecerán de nuevo en sus últimas novelas de senectud, como El duque de Alcira o la ya citada El crimen de Villaviciosa. La presencia de historias amorosas apasionadas, amantes adúlteros o suicidios por amor serán elementos constitutivos y representativos tanto de sus primeros relatos como de las novelas anteriormente citadas. El suicidio, por ejemplo, motivo esencial en El crimen de Villaviciosa, tendrá las mismas proporciones trágicas que en su novela de juventud Fenómenos psicológicos, editada en el Semanario Pintoresco Español en 1848. En dicha novela, de romántico desenlace, al igual que El crimen de Villaviciosa, se analizan los sucesivos cambios de carácter sentimental de un joven enamorado con frenesí de una mujer que no le corresponde sentimentalmente, despreciando el amor de otra joven a la que más tarde requebrará, desoyéndole ella mientras la inicialmente desdeñosa le ama. Complejo cúmulo de vicisitudes que abocarán al protagonista al suicidio. Incluso, sus propias teorías sobre la novela vertidas en el Semanario Pintoresco Español en época temprana encontrarán feliz eco en sus últimas novelas, pese a escribirse cuarenta años más tarde. Por ejemplo, en sus opiniones relativas a la novela y al objetivo esencial de la misma observamos que pueden encajar perfectamente en la historia narrada en su novela El crimen de Villaviciosa, pues su finalidad, entre otros aspectos, es el análisis de la sociedad misma: «Repetimos, pues, que deseamos alta moralidad y exactitud sobre todo; y si desgraciadamente son escasas las virtudes, reálcese su brillo para compensar así su número; preséntese el vicio en toda su deformidad para que inspire horror y espanto; y si el efecto ha de ser más provechoso, désele un castigo tremendo, horrible que estremezca y asuste. Después de estos, que son los puntos cardinales de nuestra doctrina, exigimos un estudio severo y concienzudo de la sociedad y de sus costumbres, y un diseño fiel de sus cualidades distintas, con el fin de que en los siglos venideros sirva de luz para estudiar la época presente» (Navarrete, 1847: 131 $)^{10}$. La novela El crimen de Villaviciosa, pese a estar escrita en

recordaré El grumete, Clara Harlowe, Deshonor por gratitud, Con amor y sin dinero, El robo de un hijo y La soirée de Cachupín» (1909:261-262).

10. Ramón de Navarrete establece también los lindes entre la novela histórica y la novela por él preferida, la que refleja la sociedad de su época: «Revolviendo cronicones, investigando manuscritos, estudiando profundamente la historia es fácil hacer retratos que sorprendan y cautiven por su maravillosa semejanza; referir las batallas más célebres y sangrientas; describir minuciosa y cumplidamente el traje de éste, la armadura de aquél, el casco del otro; lo que no es posible por mucho que se desentierren pergaminos, es ilustrar a la generación presente en lo que es relativo a sus vicios propios, a sus instintos y a las leyes que la mueven y la gobiernan. Aquí es donde nosotros 
1882 y publicada en 1883, se ajusta en gran medida a los postulados teóricos que sobre el género novela emitió el propio Navarrete en el año 1847 desde las páginas del Semanario Pintoresco Español, pues en dicha novela se destaca la moralidad y el pundonor de los personajes, se describe el vicio como modelo antagónico a seguir y se engarza el mundo de ficción en un contexto social perfectamente conocido por el autor. Los vicios, las leyes que rigen la sociedad y las circunstancias históricas que sirven de marco a la narración serán también líneas fundamentales para el novelista, cuya única misión será trasladar al lector un retrato fiel de la sociedad.

El prologuista de El crimen de Villaviciosa, Eusebio Blasco, célebre escritor costumbrista y colector, al mismo tiempo, de colecciones costumbristas, como Madrid por dentro y por fuera $(1873)^{11}$, destaca, entre otros múltiples aspectos, su condición de cronista y conocedor de la aristocracia, de la vida madrileña en general: «Treinta y tres años ocupándose constantemente de una sociedad como aquella, tan susceptible y tan vanidosa; llenando constantemente con nombres propios las columnas de La Época [...] Los lectores de un periódico como La Época, que necesitan saber y comentar siete veces a la semana el baile de la condesa, el pañuelo blanco de la generala, la rosa amarilla de brillantes de la señora del banquero, el pleito de los Sandoval, los dominós blancos de las incógnita de la Ópera, y las soirées de tantos cachupines con dinero [...] Verse en mil ocasiones a aludir al duelo provocado por las coqueterías de Fulana, el rapto de la hija del marqués, el escándalo habido en el matrimonio A*** [...] Las crónicas de Navarrete, reunidas en tomos, serían la historia de nuestro mundo de Madrid y un arsenal de noticias curiosas ¡Cuántos cambios en la fortuna! ¿Qué almacén de dramas, comedias y novelas!» (El crimen de Villaviciosa, 1883, Prólogo, IX-XI).

El crimen de Villaviciosa se adelanta en varios años a otras novelas ambientadas en la sociedad de buen tono, en un contexto aristocrático, como en el caso de La Vizcondesa de Armas (1887) del marqués de Figueroa, La Montálvez (1888) de Pereda o Pequeñeces (1890-1891) del padre Coloma. La novela de Navarrete, publicada en 1883, pese a estar engarzada su peripecia argumental en un entorno claramente aristocrático no persigue la misma finalidad que las novelas citadas. Pereda, por ejemplo, satiriza la nobleza, su corrupción, su venalidad política y sus secretos manejos

fijamos el terreno legítimo del novelista, aquí es donde está la importancia verdadera del objeto; aquí es donde puede hacer alarde de su espíritu de observación, de su santa filosofía, de su severa moralidad» (Navarrete, 1847:23)

11. Para un estudio de la citada obra y colecciones costumbristas publicadas en la segunda mitad del siglo XIX, vid. Ayala (1993). Recientemente se ha editado dicha colección (Ayala, 2007). 
masónicos. El marqués de Figueroa se centra en los males que aquejan a la aristocracia, como la deplorable gestión económica, el afán suntuario y la frívola holganza. El padre Coloma en su sátira violenta de la nobleza durante la época de la Restauración alfonsina se centra, especialmente, en las intrigas aristocráticas, en los manejos de las sociedades secretas, en un ámbito social refinado y decadente que no luchó lo suficiente para preservar las prerrogativas de la Iglesia tras los sucesos revolucionarios. Navarrete se ciñe, fundamentalmente, al terrible episodio de un crimen cometido en una villa propiedad del duque de San Genaro. Su muerte, la del propio duque, provocará una serie de lances que finalizará con la inculpación del marqués de Valle Alegre, y su condena a la pena capital. Su pasado amoroso con la duquesa de San Genaro y sus respuestas poco convincentes durante el interrogatorio serán los argumentos esgrimidos por la fiscalía para su acusación. Sólo unas horas antes de su ejecución saldrá a escena el verdadero culpable: un hombre honrado que por venganza ha dado muerte al duque por requerir de amores a su prometida. Final feliz y nuevo reencuentro amoroso entre la duquesa, ya viuda, y el marqués de Valle Alegre. En la novela no se satiriza la venalidad política de la aristocracia, su deplorable gasto económico o su corrupción, simplemente se describe su comportamiento, sin adentrarse en honduras. Incluso en el ánimo de Navarrete se percibe una actitud bienhechora a la hora de enjuiciar a la nobleza, tanto la poseedora de un inmenso caudal como aquella que, arruinada por negocios y situaciones adversas, ha sabido enriquecerse sin utilizar ardides o artimañas venales. Lo realmente censurable en la novela es la imposición del matrimonio por parte de padre o progenitores que, arruinados, utilizan a sus hijas como moneda de cambio, sin importarles sus sentimientos. Se trata, en definitiva, del clásico triángulo amoroso, en el que el marido, el duque, por despecho amoroso, burla a su esposa con constates aventuras galantes. La razón no es otra que el desprecio de su mujer, a su situación matrimonial impuesta por un padre arruinado que la empuja a los brazos del duque, cuya fortuna es proverbial. Ella, en silencio, siempre amará a su primer y único amor, el marqués de Valle Alegre, condenado, inicialmente, por la justicia a la pena de muerte por ser el principal sospechoso del crimen.

La novela, pese a ser una historia amorosa enmarañada en un terrible crimen, no desdeña la sátira política. A diferencia, por ejemplo, de los anteriores novelistas citados - marqués de Figueroa, Pereda y Coloma-, la nobleza es considerada por Navarrete como chivo expiatorio de la Revolución Septembrina y años previos a la Restauración alfonsina. La acción de la novela transcurre durante los albores del año 1873. El crimen se comete en mayo de dicho año y la sentencia a la pena capital el 27 de julio, a tan solo dos meses de diferencia. El contexto histórico que enmarca la acción 
encaja perfectamente en los seis años comprendidos entre la Revolución de Septiembre (1868), a la que se alude indirectamente en la novela, hasta los momentos previos a la Restauración. Durante este periodo España vive pendiente de un gran problema interior -el hallazgo de una Constitución política adecuada-; y, como consecuencia, los problemas exteriores pasan a un plano secundario, tal como se percibe en El crimen de Villavcio$s a$. La política internacional interesa, fundamentalmente, en la medida en que puede contribuir a fortalecer los distintos regímenes políticos que se van sucediendo a lo largo del periodo. El problema del reconocimiento de cada cambio político por parte de las potencias extranjeras será el que más frecuentemente absorberá a los distintos ministros de Estado. Reconocimiento que se logrará fácilmente para la Revolución del 1868 y para la monarquía de Amadeo de Saboya, pero que resultará más difícil de lograr para la República de 1873, sólo reconocida desde sus inicios por dos países: Suiza y Estados Unidos. El levantamiento cantonal coincidente con la proclamación de la Primera República (1873), el inicio de la tercera guerra carlista y las jornadas revolucionarias callejeras de 1873, más virulentas, si cabe, que las décadas anteriores (1848, 1854 y 1869) provocarán un estado de desánimo y frustración que se hará patente en su novela El crimen de Villaviciosa. La peripecia argumental de la novela coincide, precisamente, con la proclamación de la República, acogida con inmensa alegría por las clases populares, pues la caída de la monarquía y sus principales acólitos, los aristócratas, significaba el final de una época ingrata y dura para los más necesitados. La república era considerada por ellos como una suprema y definitiva redención. El resentimiento y el odio, suscitados muchas veces por flagrantes atropellos, dieron lugar a situaciones violentas, azuzadas, tal como se percibe en El crimen de Villaviciosa, por un afán de revanchismo y por un extremismo visionario propio de muchos y muy diferentes grupos sociales. De todo este batiburrillo político cabe señalar que la novela de Navarrete se engarza de manera ineludible con la actitud de los radicales a raíz de la desaparición de Rojas Zorrilla. El ambiente de inseguridad ciudadana era evidente y, especialmente, en aquellos núcleos sociales en donde conviven los personajes de la novela de Navarrete, pues se trataba de una «época turbulenta y azarosa de la República de España: la guerra carlista ardía en el Norte; había partidas en muchas provincias y los forajidos se aprovechaban de la escasez de la Guardia civil para secuestrar y asesinar a las personas opulentas» (1883:135). Con tales condicionamientos no era difícil encontrar un chivo expiatorio a quien culpar de un crimen y, especialmente, si éste era aristócrata y había tenido relaciones sentimentales con la mujer del, precisamente, asesinado. El pueblo demandaba un culpable, un aristócrata, para demostrar a la sociedad que la justicia actuaba de 
la misma forma ante un crimen, sin importarle la condición social del culpable, pues los mismos derechos y responsabilidades tenían los aristócratas que los vulgares criminales. El marqués de Valle Alegre, protagonista de la novela, es el principal sospechoso, el culpable. La turba esperará con impaciencia el día de su ejecución. El tribunal ya había dictado sentencia: pena de muerte. El proceso se había llevado a cabo con una celeridad inédita, a fin de demostrar la imparcialidad de la justicia. Un contexto poco propicio para desvelar la verdad y el honor del acusado: «Todo, todo estaba en contra suya: las circunstancias políticas, el deseo de hacer un ejemplar, según se repetía a cada instante [...]» $(1883: 158)^{12}$.

El crimen de Villaviciosa, al igual que buena parte de las comedias de Navarrete, ofrece al lector historias paralelas. Si por un lado presenta la historia amorosa del ya citado triángulo amoroso, configurado por los duques de San Genaro -Carlos y Albertina- y el marqués de Valle Alegre -Ernesto-, por otro, el novelista incluye una no menos apasionada historia de amor con final trágico protagonizada por la huérfana Matilde, protegida de la duquesa, y Rugiero, secretario del propio duque. Tanto en un caso como en otro, las dos historias están imbricadas en un ambiente aristocrático, en consonancia con la etiqueta y normas establecidas por la llamada sociedad de buen tono. Ni qué decir que Navarrete se mueve como pez en el agua, pues desde época temprana había sido elegido por los editores para la descripción de los variados tipos que configuran y dan vida a la burguesía y aristocracia madrileñas. El inicio de la novela no puede ser más elocuente en este sentido. El protagonista, Ernesto, aparece como un ser misterioso, en un contexto urbano frecuentado por la llamada alta sociedad, paseándose ante los ojos atónitos de la concurrencia en un «milord azul, con coronas de marqués, tirado por dos poneys de pura sangre, a un hombre como de treinta años, de fisonomía inteligente, de mirada expresiva, de arrogante figura. Lo correcto del tren, en que no se echaba de menos ni un solo detalle de los que puede exigir el gusto más exquisito; los emblemas aristocráticos pintados en el mismo; el noble y elegante porte del que lo ocupaba; todo, todo lo justificaba semejante movimiento de interés. Las señoras volvían la cabeza al pasar el ligerísimo vehículo; los dandys y los gomosos lo examinaban con extraordinario detenimiento, y unánimes se veían obligados a confesar, las unas, que el individuo en cuestión era gallardo, y los otros

12. La prensa también avala en sus artículos este clima de crispación y su interés por castigar al culpable con la pena capital, máxime si era noble: «[...] escribían extensos artículos de fondo para asegurar que en la época venturosa en que se había entrado, no se podía demostrar mayor indulgencia con los grandes que con los pequeños: al revés, cuanto más alta fuese la posición del individuo, tanto más se le debía exigir que diese ejemplos de moralidad y virtud» (1883:159) 
que coche, criados, caballos y librea correspondían a las más severas reglas del buen tono» (1883: 16).

La residencia o palacete de los duques, así como las celebraciones tanto íntimas como familiares, son descritas con precisión y conocimiento de las mismas. Bailes, saraos, desplazamientos, paseos a caballo, comportamientos, en definitiva, de la alta sociedad que Navarrete conoce con precisión desde época temprana. Recordemos, por ejemplo, sus artículos de juventud La coqueta y El elegante, pertenecientes a la colección Los españoles pintados por sí mismos (1843-1844). No menos significativos son los cuadros costumbristas insertos en sus libros, como En el gran mundo (Sueños y realidades) o el titulado Veinticuatro horas de una mujer del gran mundo publicado en la Ilustración Española y Americana a los setenta y cinco años de edad (abril de 1893). Perfecto conocedor de las costumbres de la burguesía y la nobleza como lo demuestran también sus artículos El gran baile y El asalto, pertenecientes a la colección Madrid por dentro y por fuera (1873). Desde múltiples perspectivas Navarrete ofrece una galería de tipos que encarnan las virtudes y defectos del también llamado gran mundo. Por sus páginas desfilan los llamados señorito de ciento en boca, petimetre, currutaco, pisaverde, pirraca, paquete, dandy, fashionable, león, gomoso. Damas casaderas, dotes suculentas, coqueteos, usos amorosos característicos de la época, bailes, reuniones, círculos sociales frecuentados por la alta sociedad, entre otros múltiples aspectos, aparecen tanto en $E l$ crimen de Villaviciosa como en sus numerosos artículos o cuadros de costumbres ${ }^{13}$. Incluso, no faltan específicos tipos pertenecientes a una clase social no adinerada que intenta emular o imitar a la anterior, como la cursi o cualquier presuntuoso que alardea de una educación esmerada sin tenerla. Una sociedad del quiero y no puedo que tan admirablemente describió Galdós en sus novelas.

En El crimen de Villaviciosa existe un final feliz y, al mismo tiempo, trágico. Señalábamos con anterioridad la presencia de dos historias paralelas; una, protagonizada por el consabido triángulo amoroso -Ernesto, Carlos y Albertina- que se resuelve con la muerte violenta de Carlos, duque de

13. Los retratos de los principales personajes de la novela se adecuan perfectamente al canon de belleza de la época. Sus ademanes, porte y gestos serán también elementos definidores de su pertenencia a una clase social privilegiada. Por ejemplo, el marqués de Valle Alegre, Ernesto, aparece siempre como hombre de figura elegante, bello, melancólico y de maneras distinguidas. Albertina, la esposa del duque San Genaro, será mujer de «elevada estatura, flexible talle, pie pequeño, rostro de una pureza de líneas incomparables, ojos azules de melancólica expresión, cabello rubios cenicientos [...]» (1883: 39-40). Ellos serán siempre de varonil belleza. Ellas, elegantes, sobrias, sencillas y mesuradas y de una parquedad o frugalidad poco comunes, como en el caso de Albertina. 
San Genaro, y el casamiento entre Albertina, viuda a raíz de la muerte de su esposo, con Ernesto, su primer y único amor. Final feliz que se consigue gracias a la muerte del perverso calavera y el casamiento de los héroes inmaculados y con un alto concepto del honor y de la honra: Ernesto y Albertina. La segunda historia paralela, de final trágico, corresponde a la relación amorosa existente entre Matilde, la huérfana protegida por Albertina, y Rugiero, secretario del duque de San Genaro. Al final del relato, horas antes de la ejecución de Ernesto, aparecerá el misterioso y único asesino del duque: Rugiero. El motivo no es otro que el intento de violación del duque a Matilde. Reabierta de nuevo la causa criminal y demostrada la inocencia de Ernesto, Rugiero será condenado a la pena capital. Antes de su ejecución recibirá la visita de Matilde que, emulando la actitud de las heroínas románticas, llevará en un pomo una pócima venenosa que ingerida por los dos en el lóbrego calabozo acabará con sus vidas ${ }^{14}$. Un final sublime y con resonancias de específicas obras, especialmente de El Trovador-suicidio de Leonor-y La Conjuración de Venecia -actitud y porte de Rugiero-. Trágico final a la par que bello y sublime por la exaltación de los sentimientos de los protagonistas.

En la novela de Navarrete conviven varios elementos cuya procedencia nos remite a diversas formas de relatar los hechos y ubicar los mismos a una tendencia narrativa. Es decir; por una lado, elementos propios de la novela de folletín; por otro, una clara propensión o preferencia por las notas ambientales y descriptivas como marco esencial de la narración. Los primeros elementos del folletín los encontramos desde el inicio mismo de la narración, en el sombrío y misterioso pasado de los protagonistas, en su sufrimiento y penalidades. Sentimientos que se suceden vertiginosamente, atrapados en una maraña de acontecimientos que tras un cúmulo casuístico de desdichas se deslizan, finalmente, hacia un desenlace feliz. La presencia de huérfanos, personajes malévolos o dadivosos y con un alto concepto

14. Matilde, sabedora de que Rugiero es el salvador de su honor y honra, le hace la siguiente proposición: «Tú mueres por mí, Rugiero, yo debo morir por ti. Y como el siciliano lanzase una exclamación de sorpresa, Matilde le miró apasionadamente, sacó del seno un pequeño pomo de cristal y se lo mostró con una sonrisa triste: -Mira,- le dijo muy bajo, como si temiese ser oída; -hay bastante para los dos. Rugiero la estrechó de nuevo entre sus brazos con extremos de frenética alegría.- $\mathrm{Su}$ único deseo iba a cumplirse: Matilde no pertenecería a otro hombre. Cuando se hubieron calmado los transportes de su júbilo, preguntóla ansiosamente: - ¿Y morirás contenta? -¡Moriré feliz! -respondió ella con decisión. -¡Apresurémonos! -dijo Rugiero apoderándose del pomo fatal y llevándole presuroso a los labios. Entregósele enseguida a Matilde, quien lo apuró con igual presteza. Entonces los dos amantes se enlazaron estrechamente; el rostro sobre el rostro, los labios sobre los labios, las manos unidas cariñosamente. Cuando media hora después entró el alcalde en la prisión, ambos parecían dormidos. Sí -¡dormían el sueño eterno!» (183: 233-234). 
del honor serán, igualmente, ingredientes fundamentales en la novela de Navarrete. Por ejemplo, Matilde, personaje de gran trascendencia en El crimen de Villaviciosa, es huérfana, carece de recursos económicos y no tiene familia Sólo la caridad y la amistad de la duquesa, Albertina, servirán de paliativos ante tanta desdicha. Otro tanto sucede con Rugiero, convertido en secretario del duque al quedar huérfano. La irrupción de individuos cuyas señas de identidad son la malevolencia, el resentimiento y el rencor, como en el caso del perverso barón de Almadén, cuyas diabólicas calumnias convertirán al generoso y dadivoso protagonista en principal sospecho del crimen, dará al relato un tinte folletinesco. El mismo asesinato y la presencia abundante de sangre en el escenario del crimen son también fáciles recursos del folletín, al igual que las opiniones claramente contradictorias de quienes juzgan el hecho. Frente a estos ingredientes o recursos cabe senalar la presencia de un contexto urbano que nos remite al Madrid previo a la Restauración: los paseos de moda, jardines, círculos sociales... El paseo de la Castellana, el más frecuentado por la alta sociedad en esta época, la fuente del Obelisco, con un cisne de piedra, procedente del convento de San Felipe el Real, son las primeras señas de identidad que aparecen en la novela. La Puerta del Sol, la calle Argensola, con entrada por la del Barquillo y salida a la de Génova, el Veloz-Club, el hotel de la Paz, el café Fornos, el convento de las Salesas, el Saladero, etc. son referentes claros de un Madrid urbano que actúa como ente receptor de los sucesos acaecidos en El crimen de Villaviciosa, una novela, en definitiva, que se proyecta desde diversas tendencias y participa de varios elementos propios del folletín y de la novela de costumbres. Una sociedad que juzga un crimen cometido en un momento histórico harto conflictivo y que se resuelve gracias a la generosidad de sus personajes, pues la justicia y sus representantes, obcecados por el revanchismo político, sólo buscan un culpable, un chivo expiatorio. En este sentido cabe señalar que Ramón de Navarrete, Asmodeo, no sólo fue el más destacado cronista de la alta sociedad de su época, sino también uno de sus valedores más significativos, consciente de que su novela tendría feliz acogida y lectura en dicho contexto social. 


\section{BIBLIOGRAFÍA}

Anales dramáticos del crimen. Causas célebres españolas y extranjeras extractadas de los originales y traducidas bajo la dirección de Don José Vicente y Caravantes, doctor en jurisprudencia, Madrid, Imprenta de Gaspar y Roig, editores, 1860.

Angelón, Manuel, Crímenes célebres españoles. Colección de [...] redactada por algunos distinguidos [...] escritores, dirigida por..., Madrid, Librería Española, Barcelona, I. López Bernagos, 1859.

Ayala, $\mathrm{M}^{\mathrm{a}}$ de los Angeles, Las colecciones costumbristas (1870-1885), Alicante, Servicio de Publicaciones de la Universidad de Alicante, 1993.

—. (ed.), Madrid por dentro y por fuera, Madrid, Biblioteca Nueva, 2008.

Blanco y GaRCía, Francisco, La literatura Española en el siglo XIX, Madrid, Saenz de Jubera Hermanos, editores, 1909, vol. I.

Brown, Reginald F., La novela española. 1700-1850, Madrid, Dirección General de Archivos y Bibliotecas, 1953.

—. «La novela realista dentro del romanticismo», en Acta Salmanticensia, Sección de Filosofía y Letras, X (1956), pp. 495-503.

Cavestany, Genaro, Memorias de su setentón sevillano, Sevilla, Tipografía Gironés, 1917-1918.

Cueto, Leopoldo Augusto, Revista de Madrid. Segunda época, I, 1843.

Fernández Almagro, Melchor, Cánovas. Su vida y su política, Madrid, Ediciones de Ambos Mundos, 1951.

FreiXÁ y Martí, D., El mundo del crimen. Reseña típico histórica de la criminalidad moderna en todo cuanto abarca y Código Penal... láminas sueltas y retratos por M. Moliné y L. Labarta, precedida de un prólogo de R. Ll., Barcelona, 1888.

Madrid por dentro y por fuera. Guía de forasteros incautos. Misterios de la corte, enredos y mentiras, verdades amargas, fotografías sociales. La familia, la calle, el paseo. Cuadros de costumbres, miserias madrileñas, lujo y bombolla. Tipos de Madrid, señoras, caballeros, políticos y embusteros. Lo de arriba, lo de abajo, lo de fuera, lo de dentro. Madrid tal cual es. Madrid al pelo, Madrid en camisa. Dirigido por Eusebio Blasco y escrito por varios autores, Madrid, A. de San Martín y Agustín Jubera, 1873.

Martín Rocha, Lorenzo, El crimen de Berzocana y causas esenciales de la criminalidad, Madrid, J. A. García, 1880.

Martínez ÏNIQuez, J. M., Crimen, venganza y expiación. Novela original, Madrid, Imprenta de J. A. García, 1863. 
MaXiriarth [seudónimo de Juan Eugenio Hartzenbusch], Unos cuantos seudónimos de escritores con sus correspondientes nombres verdaderos. Apuntes recogidos y seleccionados por..... Madrid, Tipografía de Manuel Ginés Hernández, Impresor de la Real Casa, 1892.

Miracle Carbonell, Federico, El crimen de la calle Moncada, Barcelona, Imprenta El Diluvio, 1886.

- El crimen de la calle Moncada. Facsímile de los principales documentos que obran en la causa, y demostración de la manera importantísima con que el arte caligráfico contribuyó al descubrimiento de tan horrendo crimen, Barcelona, Tipografía de la Casa de Caridad, 1887.

Morales Sánchez, F., Páginas de sangre. Historia del Saladero por F. Morales Sánchez, precedida de un notable episodio crítico criminal por Victor Hugo, titulado «El último día de un reo de muerte», traducido por uno de nuestros más aventajados jurisconsultos, y de un estado alfabético de seiscientos cuarenta y nueve desgraciados que han subido al patíbulo en Madrid, desde el año 1801 hasta la fecha, Madrid, Oficinas y Administración Tipográfica de Tomás Rey, 1870-1871.

Navarrete, Ramón de, Ciencias y desengaños, Madrid, Viuda de Jordán e hijos, 1843.

- Madrid y nuestro siglo. Novela, Madrid, Viuda de Jordán, 1845-1846.

—. «Literatura. La novela española», Semanario Pintoresco Español, Año XII. Nueva época, Tomo II, 1847, pp. 82-84, 117-119 y 130-131.

- Fenómenos psicológicos, Semanario Pintoresco español. Nueva Época, XIII, 1848, pp. 310-312, 326-327, 334-336 у 350-352.

- Misterios del corazón. Novela, Sevilla, Francisco Álvarez y Cía., 1849.

- Verdades y ficciones. Prólogo de Luis Mariano de Larra, Madrid, Imp. M. A. de Carlos, Ilustración Española y Americana, 1874.

-. Sueños y realidades, por D... Con un prólogo de Don Carlos Coello, Madrid, Ilustración Española y Americana (Aribau y Ca), 1878.

- El crimen de Villaviciosa por D. Ramón de Navarrete (Asmodeo) con prólogo de D. Eusebio Blasco, Madrid, Imprenta de El Día, 1883.

Rubio Cremades, Enrique, «Entre el relato policíaco, realista y pseudofolletinesco: Piedad, historia de una joven desgraciada, de Mariana de Mendoza», en Lectora, heroína, autora (La mujer en la literatura española del siglo XIX). Actas del III Congreso de la Sociedad de Literatura Española del Siglo XIX, V. Trueba, E. Rubio, P. Miret, L. F. Díaz Larios, J. F. Borrel y L. Bonet (eds.), Barcelona, PPU, 2005, pp. 321-331.

El sacamantecas. Su retrato y sus crímenes, Vitoria, Viuda e Hijos de Iturbe, 1881 . 
Sáez Domingo, A., Procesos civiles. Aldomar. Asesinatos del estanco de la calle de la Unión (Tarragona), Madrid, 1884.

—. Proceso de Mierra... por la muerte de Juan Maza, Madrid, 1884.

—. Proceso «Morillo». Asesinatos de la calle de San Vicente, Madrid, 1884.

-. Procesos del Solar y la Mano Negra y otros, Madrid, 1884.

- Procesos célebres. Crónicas de los tribunales españoles, Madrid, 1885.

SEbold, Russell P., En el principio del movimiento realista .Credo y novelística de Ayguals de Izco, Madrid, Cátedra, 2007.

Zavala, Iris M., Ideología y política en la novela española del siglo XIX, Salamanca, Ediciones Anaya, 1971. 